\title{
El movimiento cocalero y su (in)existencia en el Perú. Itinerario de desencuentros en el río Apurímac
}

Le mouvement des producteurs de coca et son (in)existence au Pérou. Itinéraire de mésententes dans la région du fleuve Apurímac

The coca growers movement and its (non) existence in Peru. An itinerary of the failure to coalesce in the Apurimac River region

\section{Anahí Durand Guevara}

\section{(2) OpenEdition}

\section{Journals}

Edición electrónica

URL: http://journals.openedition.org/bifea/5651

DOI: 10.4000/bifea.5651

ISSN: 2076-5827

Editor

Institut Français d'Études Andines

Edición impresa

Fecha de publicación: 1 mayo 2005

Paginación: 103-126

ISSN: 0303-7495

\section{Referencia electrónica}

Anahí Durand Guevara, « El movimiento cocalero y su (in)existencia en el Perú. Itinerario de desencuentros en el río Apurímac », Bulletin de l'Institut français d'études andines [En línea], 34 (1) | 2005, Publicado el 08 abril 2005, consultado el 01 diciembre 2020. URL : http:// journals.openedition.org/bifea/5651 ; DOI : https://doi.org/10.4000/bifea.5651

\section{cc) (†) $\odot$}

Les contenus du Bulletin de l'Institut français d'études andines sont mis à disposition selon les termes de la licence Creative Commons Attribution - Pas d'Utilisation Commerciale - Pas de Modification 4.0 International. 


\title{
El movimiento cocalero y su (in)existencia en el Perú. Itinerario de desencuentros en el río Apurímac
}

\section{Anahí Durand Guevara*}

\begin{abstract}
Resumen
El presente artículo aborda los principales esfuerzos y limitantes de los campesinos productores de hoja de coca (cocaleros) para constituirse en un «movimiento social» capaz de problematizar consensos culturales presentes en la sociedad civil e incidir, a la vez exitosamente, en el terreno político. Resume además parte de lo trabajado en la investigación sobre política y democracia en las cuencas cocaleras en el marco de la beca IFEA-IEP.

En los dos primeros puntos, se caracteriza el escenario regional. Se analizan, tanto las características demográficas y socioeconómicas del valle del río Apurímac, como los procesos históricos y políticos, signados por la violencia política y el narcotráfico; factores que influyen decisivamente en la identidad del actor, haciéndola débil y confrontacional.

Los dos puntos siguientes profundizan en la problemática de la acción colectiva, acercándonos a las principales estrategias organizativas y los esfuerzos por socializar el conflicto de los actores. En cuanto a las estrategias, estas se caracterizan por las dificultades al definir adversarios y la presencia de caudillismos y componentes pragmáticos que aportan al aislamiento y la fragmentación. No es posible así articular una agenda cocalera nacional, ni establecer alianzas con otros actores sociales que enriquecerían la acción colectiva. Finalizamos llamando la atención sobre la importancia de atender la problemática cocalera desde los canales democráticos, como la mejor vía para evitar nuevas situaciones de exclusión, polarización y violencia.
\end{abstract}

Palabras claves - cocaleros, movimiento social, escenario regional, valle del río Apurímac, identidad, estrategias organizativas, acción colectiva

* Socióloga graduada en la Universidad Nacional Mayor de San Marcos, becaria del convenio IFEA-IEP 2004, para investigadores jóvenes. Correo electrónico: anahi@iep.org.pe 


\title{
Le mouvement des producteurs de coca et son (in)existence au Pérou, Itinéraire de mésententes dans la région du fleuve Apurímac
}

\section{Résumé}

Le présent article traite des principaux efforts et limitations des cultivateurs de feuilles de coca (cocaleros) pour se constituer en un «mouvement social» capable de présenter le problème les consensus culturels présents dans la société civile et, à la fois, d'intervenir efficacement sur le terrain politique. De plus, il résume une partie des progrès accomplis dans la recherche sur la politique et la démocratie dans les vallées productrices de coca, réalisée dans le cadre de la bourse IFEA-IEP.

Les deux premières parties permettent de cerner le scénario régional. On y analyse tant les caractéristiques démographiques et socio-économiques de la vallée du fleuve Apurímac que les processus historiques et politiques, marqués par la violence politique et le trafic de stupéfiants, facteurs qui exercent une influence décisive sur l'identité de l'acteur, la rendant extrêmement variable.

Les deux parties suivantes approfondissent la problématique de l'action collective, en regardant de près les principales stratégies d'organisation et les efforts déployés pour partager l'information sur le conflit des acteurs. Ces stratégies se caractérisent par les difficultés à définir les adversaires et par la présence de caudillismes et de composants pragmatiques qui contribuent à l'isolement et à la fragmentation. Il est ainsi impossible d'articuler un plan d'action national des producteurs de coca ou de nouer des alliances avec d'autres acteurs sociaux qui enrichiraient I'action collective. En conclusion, nous attirons l'attention sur l'importance de s'attaquer à la problématique des producteurs de coca par des voies démocratiques, comme étant la meilleure façon d'éviter de nouvelles situations d'exclusion, de polarisation et de violence.

Mots clés - cocaleros, mouvement social, scénario régional, vallée du fleuve Apurímac, stratégies d'organisation, action collective

\section{The coca growers movement and its (non) existence in Peru, An itinerary of the failure to coalesce in the Apurimac River region}

\begin{abstract}
This article explores the principle efforts and limitations by the peasant producers of the coca leaf (cocaleros) to constitute themselves into a new «social movement» capable of problematizing civil society's cultural consensus, while also successfully participating in the political terrain. Furthermore, this article summarizes part of the IFEA- IEP fellowship research conducted on policy and democracy in the drainages where coca is grown.

The article's first two points address the regional scenario. These analyze the demographic and socio-economic characteristics of the Valley of the Apurimac River as well as its historic and political processes, which have been marked by political violence and drug trafficking. These factors have decisively influenced the actor's identity, making it weak and confrontational.

The two following points of the article delve deeper into the problematic of collective action by addressing the principle organizational strategies and the efforts to socialize the conflict between the actors. These strategies can be characterized by their difficulties in defining adversaries, and the presence of strong leaders (caudillismos) and pragmatic components that support isolation and fragmentation. It is thus not possible to articulate a national agenda for the coca growers, nor to establish alliances with other social actors that could enrich collective action. The article concludes by calling attention to the importance of attending to the coca problematic through on democratic channels as the best manner to avoid new situations of exclusion, polarization, and violence.
\end{abstract}

Key words - cocaleros, social movement, regional scenario, valley of the Apurimac river, identity, organizational strategies, collective action 


\section{EL ESCENARIO REGIONAL}

El valle del río Apurímac Ene (VRAE) se ubica entre las regiones de Ayacucho y Cusco, abarcando distritos de la provincia de Huanta (Llochegua y Sivia), de la provincia de La Mar (Ayna, Santa Rosa, San Miguel, Anco y Chungui), y los distritos cusqueños de Quimbiri, Pichari y Vilcabamba, de la provincia La Convención. También abarca el distrito de San Martín de Pangoa en la región Junín. El Valle abarca un área de extensión aproximada de $12081 \mathrm{~km}^{2}$ situados entre los 400 y 2500 msnm, cuenta con un clima tropical lluvioso y temperaturas que varían entre los 22 y $28^{\circ} \mathrm{C}$. La configuración topográfica del VRAE se caracteriza por las elevadas pendientes a ambas márgenes del río Apurímac, lo cual eleva los niveles de erosión del suelo, agravado por la tala del bosque y el incremento de la frontera agrícola las tres últimas décadas.

\section{Cuadro 1 - Población y superficie del valle del Apurímac}

\begin{tabular}{|c|c|c|c|}
\hline Distritos & $\begin{array}{c}\text { Población } \\
\text { Total }\end{array}$ & $\begin{array}{c}\text { Superficie } \\
\text { km² }^{2}\end{array}$ & $\begin{array}{l}\text { Fecha de } \\
\text { creación }\end{array}$ \\
\hline $\begin{array}{l}\text { A. Margen izquierda (Ayacucho) } \\
\text { Provincia de Huanta } \\
\text {. Dist. Sivia } \\
\text {. Dist. Llochegua } \\
\\
\text { Provincia de la Mar } \\
\text {. Dist. Ayna San Francisco } \\
\text {. Dist. Santa Rosa } \\
\text {. Dist. San Miguel } \\
\text {. Dist. Anco } \\
\text {. Dist. Chungui }\end{array}$ & $\begin{array}{rl}9 & 320 \\
8 & 318 \\
17 & 926 \\
14 & 113 \\
5 & 575\end{array}$ & $\begin{array}{r}280,34 \\
372,27 \\
902,98 \\
1098,20 \\
1060,52\end{array}$ & $\begin{array}{c}6.11 .1992 \\
15.09 .2000 \\
\\
17.1 .1995 \\
06.11 .1992 \\
\text { Época Indep. } \\
\text { Época Indep. } \\
\text { Epoca Indep. }\end{array}$ \\
\hline $\begin{array}{l}\text { B. Margen Derecha (Cusco) } \\
\text { Provincia de La Convención } \\
\text {. Dist. Quimbiri } \\
\text {. Dist. Pichari } \\
\text {. Dist. Vilcabamba }\end{array}$ & $\begin{array}{l}51962 \\
19393 \\
19977 \\
12592\end{array}$ & $\begin{array}{r}6911,61 \\
1134,69 \\
730,45 \\
5046,47\end{array}$ & $\begin{array}{l}4.5 .1990 \\
7.8 .1995 \\
2.1 .1857\end{array}$ \\
\hline
\end{tabular}

Fuente - INEI, Banco de información distrital 1995-2000.

Vale señalar que los distritos de San Miguel, Anco y Chungui abarcan también zonas de sierra, dificultándose registrar con exactitud la población del Valle y su superficie. Según los últimos aproximados censales, esta población ascendería a 140 304; de este total, el 65 \% de la población vive en la margen izquierda y el otro 35 \% en la margen derecha (Cusco). El centro poblado más importante es San Francisco, lugar donde se concentran la mayoría de entidades estatales y también organismos privados.

En cuanto a los indicadores demográficos, la mayoría de la población tiene necesidades básicas insatisfechas y carencia de servicios (Atlas departamental del Perú, 2003a; 2003b). En el caso de la tasa de analfabetismo, esta llega a 31,5 \% en la provincia de Huanta y a $32,8 \%$ en La Mar, porcentajes altos para la tasa promedio nacional $(10,7 \%)$. En cuanto 
a población con diferentes tipos de carencias, el 26,1 \% de la población de Huanta y el 27,1 \% en La Mar presenta Necesidades Básicas Insatisfechas (NBI). Respecto al Índice de Desarrollo Humano (IDH), tanto Huanta como La Mar se sitúan en un nivel bajo con 0,469 y 0,418 respectivamente. La provincia mejor situada es La Convención, con un IDH de rango medio bajo $(0,52)$.

El crecimiento poblacional del VRAE ha estado signado por los procesos de colonización, iniciados a fines del siglo XIX y alentados generalmente por la rentabilidad económica de algún producto agropecuario: la caña de azúcar, el cube (barbasco), el café o la coca. A diferencia de la cuenca del Huallaga, ocupada por migrantes de diversas regiones del país, la colonización del río Apurímac fue hecha por campesinos provenientes de las provincias del norte ayacuchano, que prolongan así un espacio cultural homogéneo reproduciendo sus costumbres y tradiciones. Según la encuesta Winrok (Bedoya, 2003), el 49 \% de los jefes de familia del valle nacieron en la provincia de Huanta, 28 \% en La Mar y 14 \% en Huamanga. Estos pobladores, que son en un 75 \% bilingüe quechua y castellano, mantienen la ligazón con sus pueblos de origen, visitándolos en promedio dos veces al año, fechas en las que realizan «trueques» o intercambios de productos selváticos por andinos y viceversa.

En cuanto a las actividades económicas, la agricultura es la actividad predominante del VRAE desde que se produjeron las primeras oleadas migratorias. Históricamente, por ejemplo, el valle del río Apurímac ha sido zona de colonización cocalera, especialmente el norte de la provincia de Huanta, donde a inicios del siglo XIX, existían decenas de propiedades productoras de coca en lo que fue territorio de la Intendencia de Huamanga. Los colonos, convivían en un inicio con los asháninkas o «campas», nativos cazadores y recolectores que, conforme se incrementó la migración, fueron despojados de sus tierras desplazándose cada vez más selva adentro en los terrenos de la margen izquierda o hacia el norte, por el Ene. Ya a inicios del siglo XX, los agricultores priorizan los cultivos de café, caña de azúcar y también coca, que es destinada al consumo tradicional en la sierra sur. Posteriormente en la década de 1960, por sus altos precios en el mercado internacional, el cacao y el cube se posicionan como los principales cultivos. No obstante, esta situación varía pronto, pues tanto la caída de los precios de estos productos como el inicio del conflicto armado interno en la región influyen en las dinámicas productivas y prioridades de cultivo de los agricultores.

Factores como el alza de precios de la hoja, el desplazamiento del narcotráfico por la erradicación en el Huallaga y la falta de recursos para afrontar la guerra — que llevo a alianzas entre el narcotráfico y los Comités de Autodefensa- hacen que durante los años 1980 los cultivos de coca se incrementen considerablemente. Actualmente, se calcula que en el VRAE existen unas 11000 hectáreas de coca, y de cada 100 productores 87 son cocaleros y 13 no cultivan coca. Por lo general los jefes de familia cocaleros, hombres o mujeres, son más jóvenes que los no cocaleros y poseen predios que van de 0,5 a 5 hectáreas cultivadas.

La mayor cantidad de estas hectáreas cocaleras (69 \%) se ubica en la margen izquierda, correspondiente a Ayacucho, mientras en la margen derecha (Cusco) se halla el $31 \%$. Si bien los precios de la coca han tenido diversas bajas, llegando a costar por ejemplo S/. 0,41 el kilo en 1995, su recuperación hace que el campesino conserve sus cultivos a la espera de

1 El Índice de Desarrollo Humano (IDH) se obtiene combinando características en tres dimensiones: 1) ingreso, 2) logro educativo y 3) calidad y duración de la vida. En el Perú se consideran los siguientes rangos en el nivel de desarrollo humano: alto $(0,643-0,745)$, medio alto $(0,569-0,642)$, medio $(0,531-0,568)$, medio bajo $(0,473$ $0,530)$ y bajo $(0,367-0,472)$. 
una probable alza. Como se observa en el gráfico, la coca sigue siendo el producto de mayor rentabilidad -en términos de mejor precio y alta productividad - desplazando largamente a los productos de los Programas de Desarrollo Alternativo (PDA). Así, por un kilo de hoja de coca ENACO paga S/. 5,50 y los comercializadores del narcotráfico S/.11,00, bastante más que lo que se paga por un kilo de café (S/. 2,50) o de cacao (S/. 3,00), de maíz o piña cotizados a $S / .0,50$ y S/. 0,30 respectivamente.

Sin embargo el agricultor del VRAE no es mono cultivador, en las chacras, junto a la coca suele sembrar cacao, café, frutales, etc.

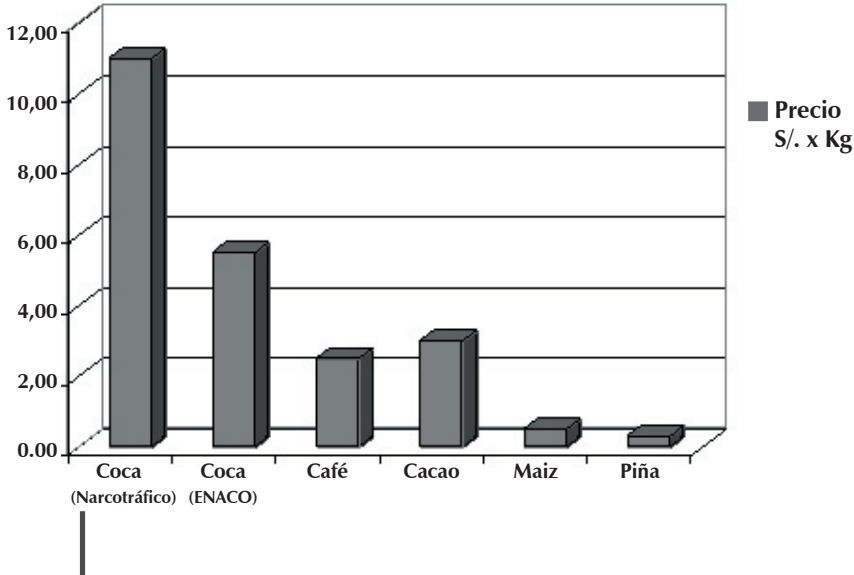

Figura 1 - Promedio de precios por cultivos en el 2004 Elaboración: Anahí Durand Fuente: www.minagricu.gob.pe Lo que existe es una estrategia de reducción del riesgo (Bedoya, 2003), donde la coca es el cultivo que minimiza pérdidas y maximiza oportunidades, en tanto permite sostener a los otros cultivos y satisfacer las necesidades cotidianas del agricultor. La coca requiere menos inversión que productos como el café o el cacao y se cosecha hasta tres veces por año, a diferencia de los otros productos: con pocos cuidados se obtienen más ingresos durante todo el año, de ahí que el agricultor considere a la coca como una suerte de «caja chica». Tal como refiere Alejandro Gutiérrez, secretario general de la FEPAVRAE:

«[...] consideramos que la hoja es complemento del producto anual, por que nuestra economía no ve dinero y estamos empleados en el campo un año sin que se generen ingresos, pero en cambio la coca da trimestral, es mas dinámico».

De otra parte, dados los vínculos que mantienen los pobladores del valle con sus familias en la sierra, la coca cumple un rol central en el trueque o intercambio de productos tradicionales serranos (cebada, maíz, chuño, papas, etc.) que continúan siendo consumidos por las familias de la selva. El VRAE es la zona agrícola más dinámica de Ayacucho, por ende la de mayor crecimiento demográfico, con un campesinado estrechamente vinculado al mercado. Este carácter predominante de la agricultura y de la producción de la coca en particular, hace que, hoy en día, una de las organizaciones sociales más importantes sea la Federación de Productores Agrarios del Valle del Río Apurímac (FEPAVRAE). Así, los principales debates y movilizaciones suscitadas en el VRAE han tenido a los cocaleros como protagonistas, enfrentados a los organismos estatales y ONG operadoras de los programas de «Desarrollo Alternativo», reclamando la salida del valle de los entes operadores, el cese de la erradicación de cultivos, entre otras reivindicaciones.

Tal situación de movilización constante hizo pensar a muchos políticos e intelectuales en el surgimiento de un movimiento cocalero que, en la línea de los «nuevos movimientos sociales» (Touraine, 1989), desde la identidad y la exigencia de autonomía, cuestione los consensos sociales y culturales vigentes, incursionando cada vez más en el terreno político. Vale analizar entonces, cómo se va configurando este movimiento social en el Perú, deteniéndonos en la dinámica organizativa de los cocaleros, a partir de algunos aportes de la teoría sociológica sobre el tema que brevemente pasamos a detallar. 


\section{MOVIMIENTOS SOCIALES: ENTRE LA REALIDAD Y LA TEORÍA}

Consideramos que el estudio de los denominados «movimientos sociales» es fundamental para comprender adecuadamente la acción colectiva de actores que, en el actual contexto, irrumpen en la escena pública reivindicando una serie de derechos y exponiendo sus demandas tanto al Estado como a la sociedad civil.

Se han desarrollado diferentes enfoques para comprender la acción y desarrollo de los movimientos sociales. Entre los denominados «Enfoques clásicos», se cuenta la denominada «teoría del comportamiento colectivo», según la cual frente a una tensión, individuos que ven perturbado su entorno social, interactúan formando grupos, aunque de modo espontáneo y desorganizado. Por ejemplo, Le Bon, en su libro Sicología de masas (1895), define a estas como:

«[...]una reunión de individuos de cualquier nacionalidad, profesión y/o sexo, asî como de las circunstancias que lo reúnen [...] entre cuyas características principales se cuenta el ser altamente sugestionables, impredecibles, emotivas y peligrosas». (Barrera, 2001)

Posteriormente, la escuela de Chicago define al comportamiento colectivo como las nuevas normas sociales, valores y creencias que surgen de las necesidades, impulsos y deseos de los individuos que no pueden ser satisfechos por las formas de vida existentes. El curso de un movimiento social es condicionado por la interacción con el régimen político institucional de su sociedad y las pugnas entre los grupos de interés; carecen además de control sobre sí mismos, lo cual los lleva a cumplir un ciclo de vida que oscila del descontento a la perturbación del orden para finalizar en algún grado o nivel de institucionalización.

Consideramos que la vertiente clásica presenta serias limitaciones para la comprensión de los movimientos actuales, dada la distancia entre el espacio y momento histórico en que es pensada y el contexto en el cual hoy vivimos. Así, a esta visión de los movimientos sociales como algo negativo primero (las masas son peligrosas) y defensista después (accionan por descontento) se suma esta suerte de determinismo cíclico. Los movimientos tendrían un fin anunciado en una institucionalización que no asegura la consecución efectiva de las demandas y que podría obstruir su potencial propositivo y transformador. Las motivaciones para participar colectivamente no residen en lograr objetivos políticos sino más bien en la necesidad de resolver tensiones psico individuales, siendo la acción colectiva una terapia social antes que la movilización en pos de objetivos sociales y políticos.

De otro lado, está la «Teoría de la movilización de recursos», que pone énfasis en el cómo, durante el proceso de movilización, se acopian los recursos necesarios para la acción colectiva. Para Tilly (1995), los movimientos sociales, mediante acciones públicas de gran magnitud y unidad dentro de un área geográfica, asumen una serie de demandas propias de una población desfavorecida. Desde este enfoque son tres los factores decisivos en el accionar de los movimientos sociales:

1. La estructura de oportunidades, es decir determinados contextos de apertura política (transiciones democráticas, la consecución de aliados influyentes en el gobierno, cambios en las correlaciones políticas, etc.).

2. Las formas de organización o los modos de desarrollar la acción que guían a los actores, según una lógica de conciencia y confrontación «heredado y apropiado culturalmente», junto a nuevas formas de convocatoria y nuevos líderes consensuales.

3. Las estructuras de movilización, o las instituciones de la sociedad a través de las cuales la gente se puede movilizar o sumar a la acción colectiva, en las que suelen primar relaciones de confianza y cooperación. 
Los movimientos sociales son así respuestas racionales de individuos organizados, que sopesan permanentemente el cuándo y el cómo, los costos y beneficios de la acción. Surgen de los conflictos pero su formación depende de los recursos, el grado de organización y las oportunidades que se presenten. Recursos como el dinero, la dedicación de los activistas o la información oportuna, hacen que los movimientos sean o no eficaces.

Si bien es cierto que este enfoque enfatiza acertadamente los procesos organizativos que enmarcan la acción, dice poco sobre los discursos y valores que la orientan, privilegiando el cómo y el cuándo sobre el porqué. Rompe también con una visión negativa del accionar social, reparando en la identificación de intereses comunes de los grupos sociales con estrategias definidas y no con simples respuestas espontáneas ante el descontento. No obstante, restringe el juego político a la confrontación con los actores estatales, dejando de lado otras dimensiones de la acción colectiva como la construcción de identidades, los cambios en la cultura, etc. Por último, la excesiva importancia a la racionalidad instrumental, deja fuera formas de acción colectiva desarrolladas en lugares donde el mestizaje occidental con culturas prehispánicas permite la vigencia de formas de acción regidas también por principios de reciprocidad.

Finalmente, mencionamos al enfoque de los «Nuevos movimientos sociales» cuyo énfasis radica en concebir al movimiento social como la articulación de proyectos colectivos, donde la construcción de identidad, la oposición y la socialización del conflicto adquieren importancia central. Para Touraine (1989) el movimiento social es el eje articulador del cambio en la sociedad pos industrial, caracterizada por el desplazamiento del trabajo y el protagonismo de la información. Son cuatro las dimensiones que diferencian a los nuevos movimientos sociales:

1. Las formas de organización que priman, se alejan cada vez más de la lógica confrontacional partidaria o sindical, desafiando el orden con reivindicaciones menos totalizadoras como la igualdad de los sexos, el respeto a la ecología, etc.

2. Son portadores de nuevos valores como la autonomía y la resistencia, en paralelo a la creación de nuevas formas de vida.

3. No se trazan como objetivo central tomar el poder, su acción se orienta a buscar mayor autonomía, por lo que actúan bajo principios de identidad, oposición y totalidad, dirigiendo su accionar a la ciudadanía antes que al Estado.

4. La búsqueda de la identidad a partir de lo cultural y simbólico y menos desde el clasismo; la identidad se construye en la acción colectiva desde la cual el individuo se reconoce como actor y politiza su vida cotidiana. Los nuevos movimientos sociales además apelan a medios no convencionales de participación dejando la vía electoral clásica.

El enfoque de los nuevos movimientos sociales incorpora una serie de elementos que buscan explicar el porqué de la acción colectiva y la importancia de la identidad del actor dentro de ella. Lo cultural y lo simbólico, junto a los cambios en la sociedad pos industrial occidental, permiten estas nuevas manifestaciones. Sin embargo, las características descritas responden a un tipo de sociedad distinta a la que nos toca en Latinoamérica, donde además de tener clases medias débiles, hay una serie de demandas «industriales» insatisfechas. Es decir, los componentes simbólicos y culturales no son suficientes para explicar las dimensiones estratégicas de la acción de sociedades poco institucionalizadas y con grandes carencias económicas y sociales.

Desde Latinoamérica podría decirse que, de acuerdo a los marcos conceptuales mencionados, no existen «nuevos movimientos sociales» claramente definidos, dado su singular proceso de modernización y desarrollo y los sentidos diversos y hasta encontrados 
que adquiere la acción colectiva —un movimiento clasista puede incorporar sentidos étnicos y rechazar el género-. Como afirma el ecuatoriano Mayorga en América Latina «los movimientos sociales responden a una lógica de conflicto, cuya raíz se encuentra en la disputa por el control del sistema político y de los recursos estatales. La acción social suele ser igualmente política» (Mayorga, 1992).

En nuestro análisis entendemos por movimiento social una red compleja de relaciones sociales que producen un sentido alternativo de la acción, donde prima la identificación colectiva de intereses, a la vez que se despliegan una serie de recursos. Los movimientos sociales además siguen una «estrategia dualista» dirigiendo sus demandas a las autoridades encargadas de solucionar sus problemas, a la vez que problematizan los modelos culturales e instituciones presentes en la sociedad. Esto sin perder de vista lo propio de nuestros países: la heterogeneidad estructural, la precaria constitución de las clases sociales, el desencuentro entre los procesos económicos y la dimensión política, la pluralidad de actores y las múltiples dimensiones en la acción colectiva (clasista, nacionalista, etc.).

Aquí, para estudiar la constitución o no de los cocaleros como movimiento social, analizaremos de un lado su dinámica organizativa y los recursos que movilizan en términos de alianzas y oportunidades, y de otro lado el proceso de construcción de identidad, identificación de adversarios y socialización del conflicto, características propias de un movimiento social desde el enfoque de los «nuevos movimientos sociales». ¿Cómo se desarrolla la organización cocalera, con qué aliados y en qué oportunidades? ¿Cómo construyen identidad? ¿Sobre la base de qué criterios definen adversarios? ¿Qué elementos caracterizan la interacción con la sociedad civil y el Estado? Para responder estas interrogantes detengámonos primero en los procesos políticos sociales que han signado la vida del VRAE, influyendo en la construcción de identidad.

\section{IDENTIDADES DÉBILES, COMBINACIONES RIESGOSAS; COCA, VIOLENCIA Y NARCOTRÁFICO}

Junto con las migraciones, la violencia política y el narcotráfico han sido los factores que han marcado significativamente la vida social y política del Valle, influyendo en el reconocimiento de los productores de hoja de coca como «cocaleros». Siguiendo a Melucci (2002), la identidad colectiva viene a ser la capacidad de los sujetos para definir expectativas comunes, evaluando límites y posibilidades de la acción, a la vez que se construyen a sí mismos y su entorno. En tal sentido, veremos que en el VRAE es difícil hallar una identidad colectiva clara entre los cocaleros, pues factores como la colonización, la poca presencia estatal y el conflicto armado interno, hacen que los productores relativizen una serie de valores y percepciones. Todo esto influye además en cómo los actores entienden la política y la acción colectiva, prefigurando sus demandas, discursos y estrategias de movilización.

Respecto a las oleadas migratorias que colonizan el valle del Apurímac, estas se inician al comenzar el siglo XX contando con cierto auspicio del Estado, guiado por esquemas desarrollistas de «Colonización» de la Amazonía. Se promulga por ejemplo, durante el gobierno de Leguía, el Decreto de Tierras de Montaña, que instala en San Francisco la oficina de «Delegación de Tierras de Montaña», lugar al que acuden los colonos, provenientes sobre todo de la sierra ayacuchana, a legalizar los terrenos apropiados. Los principales cultivos introducidos en esta etapa son maíz, caña de azúcar y yuca, existiendo hacia 1907 unas 911 hectáreas de coca. Posteriormente, en la década de 1940, se produce una segunda oleada migratoria, alentada por los altos precios del «cube», cuya raíz (el barbasco) era muy utilizada en la fabricación de insecticidas. El alto precio que el cube alcanzó en el 
mercado internacional, hizo que los grandes propietarios conviertan sus haciendas en mono productoras, abriendo a la vez nuevas rutas de comercialización, incluidos tres aeropuertos en el Valle (uno de ellos en la hacienda Luisiana) (PNUFID, 1994).

En los años 1960, se produce una tercera ola migratoria, facilitada por la apertura de la carretera Ayacucho-Tambo-San Francisco, creándose una serie de nuevos centros poblados en el VRAE. En esta etapa, al boom del cube le sucede el boom cafetalero, compitiendo pequeños productores con grandes productores y comerciantes intermediarios acopiadores. Para contrarrestar la acción monopólica de los grandes propietarios y las arbitrariedades de los comerciantes, los pequeños productores se agrupan en cooperativas de producción, formándose entre 1970 y 1971 las cooperativas «Valle del Río Apurimac», «Unión Selvática» $y$ «El Quinacho». Pese a agrupar a buena parte de los agricultores las cooperativas, alentadas por el gobierno Velasquista, no logran satisfacer las expectativas de los socios por lo que en 1975 se constituye la Asociación de Pequeños Agricultores, que evoluciona en 1979 a la Federación Campesina del Valle del Río Apurímac (FECVRA), una de las más importantes organizaciones sociales de Ayacucho.

A diferencia de zonas de selva como el nor oriente peruano, el apoyo del Estado es bastante menor. Mientras en otras áreas selváticas entre los años 1970 y 1980 se conforman centros de producción agropecuaria sostenidos por políticas estatales intervencionistas, en el caso del VRA por ejemplo, ni ENCI ni el Banco Agrario, juegan un rol protagónico y tampoco se instalan centros de servicios. Esta diferenciación obedece sobre todo al interés de los gobiernos por contener la expansión de los cultivos de coca en el Huallaga, financiando por ello una serie de programas y proyectos especiales. No obstante, los pequeños productores agremiados en la FECVRA, antes que pedir mayor apoyo al gobierno, privilegian la generación de circuitos y mecanismos propios de comercialización y financiamiento, configurando una dinámica más autónoma y gestionaria que clasista y confrontacional, a diferencia de lo que sucedía en otros gremios agrarios de la época. Este proceso organizativo es interrumpido por el estallido de violencia a inicios de los 1980.

El inicio del conflicto armado interno en el VRAE puede situarse en 1982 cuando jóvenes senderistas incursionan en la zona pretendiendo apoyar las luchas de la FECVRA por asumir la comercialización de sus productos (café y cacao) en contra del monopolio de los grandes comerciantes. Siguiendo a Del Pino, la intención de Sendero Luminoso de cooptar la organización es absolutamente contraproducente, pues la FECVRA gozaba de gran legitimidad e intentaba competir limpiamente con los principales grupos de poder. Al saquear Sendero los almacenes de los grandes comerciantes, estos aprovechan la oportunidad para denunciar como responsables a los dirigentes de la FECVRA quienes son encarcelados. La situación se agrava en enero de 1983 cuando el Comando PolíticoMilitar asigna las provincias de Huanta y La Mar a la Infantería de Marina. Desde entonces la FECVRA es vista con mucha desconfianza por «los navales», cometiéndose graves abusos como el asesinato — en la hacienda Luisiana, base principal de la Marina- del líder de la FECVRA, Julio Orozco Huamani. Con dirigentes encarcelados, asesinados y otros desplazados por la violencia, el principal gremio del Valle es descabezado y deja de funcionar pese a haber reunido 103 bases. Se corta además el esfuerzo de organización autónoma de los pequeños productores y la prioridad deja de ser la agricultura; es el momento de la autodefensa.

A partir de 1984, con el fin de contrarrestar esta violencia, surgen autónomamente del Estado los comités de «Defensa Civil Antisubversiva» (DECAS) expandiéndose rápidamente por todo el VRAE (Del Pino, 1996). Al participar la gran mayoría de agricultores en las Autodefensas, disminuyen las posibilidades de dedicarse a los cultivos anuales como el cacao o el café, pues,dado el aislamiento del Valle por la violencia, no tienen salida comercial. 
La población opta por sembrar coca que, en comparación con dichos productos anuales, no demanda grandes cuidados, posibilitando a los agricultores participar de las DECAS y cultivar la hoja en sus momentos libres. En este periodo, el VRAE se vincula directamente con redes de acopio de coca y producción de pasta básica de los carteles del narcotráfico. Según la Comisión de la Verdad y Reconciliación, se establece una alianza temporal de las DECAS con narcotraficantes que pagan cupos en pleno boom del precio de la coca y sus derivados ilícitos entre 1984 y 1986. Los cupos permitieron a las DECAS comprar armas antes de que el gobierno las entregara, formando grupos de ronderos dedicados a tiempo completo conocidos como los «rentados» (CVR, 2003: tomo 4).

Palmapampa se establece como el principal centro de la droga, con presencia de narcotraficantes colombianos y mexicanos y gran circulación de dólares, aunque no en la magnitud y desmesura del Alto Huallaga. La violencia y la indiferencia estatal justifican para los productores el incremento del cultivo de coca y su comercialización al narcotráfico, aun sabiendo que esto es un delito. Es difícil sin embargo, hablar de situaciones delictivas en un contexto donde la guerra trastoca los valores, haciéndose cotidiano robar, matar, violar o vender droga. Los dirigentes de la época no niegan la alianza con el narcotráfico, por el contrario la reconocen en una suerte de reclamo por la desatención estatal. Al respecto, son ilustrativas las declaraciones de Francisco Barrantes «Pachin», comando del DECAS de Pichari y secretario general de la FEPOHCRA (Federación de Productores de Hoja de Coca):

«Sería mentir negar que hubo una alianza estratégica narcotráfico y autodefensas. Esa alianza hizo que la gente tome fuerza, se armen mejor los DECAS, por eso cuidamos a la coca, si no hubiera habido coca no hubiéramos logrado la pacificación; la coca ha sido el recurso que ha financiado el mantenimiento familiar de los comandos. Aquí se ha invertido millones, se han hecho miles de operativos y todo el costo lo ha pagado la coca, además en tiempo de guerra la coca era el único producto que podíamos mantener por que tenía mercado local y salida».

La pacificación del valle del río Apurímac genera una violencia nunca antes vista, donde los distintos actores de la guerra (FFAA, Sendero, DECAS) cometen numerosas atrocidades aún impunes. Con la violencia, se incrementa también la presencia de iglesias evangélicas, en parti-cular la Iglesia Pentecostal, caracterizada por su mensaje fundamentalista de tintes apo-

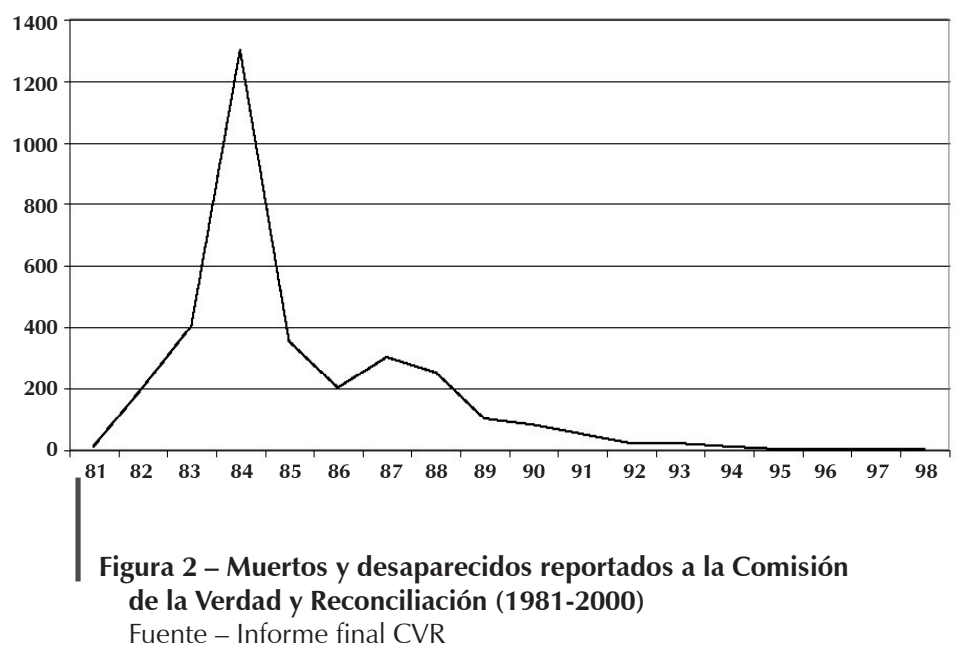
calípticos. La expansión de estas doctrinas, indica a la vez, la necesidad de nuevos sentidos y esperanzas en tiempos de crisis (Del Pino, 1996).

Solo a fines de 1989, el gobierno entrega armas a las Autodefensas del VRAE, estableciéndose una relación de coordinación más fluida con el ejército. Para ese momento, prácticamente todas las provincias norteñas de Ayacucho se hallan organizadas en Comités de Autodefensas. A partir de 1993, la violencia política declina en la zona, aunque los 
DECAS son hasta hoy uno de los actores más importantes de la región, con gran influencia política y económica. Reconocimiento que se ve respaldado durante el gobierno de Fujimori y su particular discurso «pacificador», que resalta el papel de las Fuerzas Armadas, y presenta a las DECAS (denominados coloquialmente «ronderos») como defensores de la patria contra el terrorismo, en un esfuerzo por legitimarse ante estos campesinos.

Pasada la etapa de mayor violencia, decae también la actividad de los Comités de Autodefensas. En tanto la presencia de Sendero Luminoso disminuye, quedan muchos ronderos libres para volver a las actividades agrícolas en sus parcelas donde el principal cultivo ahora es la hoja de coca. Desde mediados de 1980 el valle del río Apurímac se consolida como la segunda cuenca cocalera del país, superada solo por el Alto Huallaga. Los productores organizan la Federación de Productores de Hoja de Coca del Río Apurimac (FEPOHCRA) que entra en funciones en 1995 en plena crisis del precio de la coca, pero con el apoyo de la cooperación internacional, sin que esto signifique que dependan de ella por completo. Años después (2000) en medio de disputas internas y amenazas de erradicación, se cambia el nombre a Federación de Productores Agropecuarios del Valle del Río Apurímac y Ene (FEPAVRAE), abandonando el término de productores cocaleros por el genérico de productores agrarios.

Superado el conflicto armado interno, los agricultores no regresan a la dinámica anterior de cultivo y comercialización de café, cacao y cube; los mantienen en la parcela sí, pero no son los productos prioritarios. La coca ya se ha instalado en las chacras y cuenta con un mercado seguro, mientras que volver a los cultivos anteriores implica reconstruir una serie de redes que requieren de mayor inversión y apoyo externo para obtener resultados a largo o mediano plazo. Los actores optan así por adecuar sus labores a la realidad heredada del conflicto armado, reconvirtiendo y ampliando también sus identidades; los comandos de autodefensas de ayer, también pueden ser cocaleros o simplemente agricultores, en todos los casos, cuentan con la legitimidad ganada en el enfrentamiento con los subversivos.

De otro lado, los productores incursionan en la vida pública con los códigos de política aprendidos en la guerra, donde se imponen la polarización, la verticalidad, el autoritarismo y las urgencias coyunturales propias de un escenario de conflicto. Más aún, en tanto los agricultores del VRAE consideran que ellos se enfrentaron a Sendero antes que el Estado, buscaron sus fuentes de financiamiento y se pusieron al frente en las operaciones combinadas con el ejército; es difícil que una vez lograda la pacificación, acaten lo que actores externos les dicen que deben cultivar en sus chacras. La autonomía ganada se impone y apelar a la legalidad en un contexto donde la guerra relativizó valores y percepciones resulta bastante complicado.

Junto a estas consideraciones relacionadas a la violencia, el elevado incremento de las áreas destinadas al cultivo de coca y la afirmación de los agricultores en continuar cultivándola, se hallan también razones de carácter estructural. Entre estas destacan el fracaso de las políticas de colonización, la desarticulación espacial de las zonas de producción con centros de consumo o de demanda alimentaria y los bajos niveles de productividad física de los suelos de selva (Wachholtz, 1996). A esto se agrega la caída de los precios internacionales de productos tropicales como el café, el cacao y el azúcar, y las políticas de ajuste que desarrolla el gobierno fujimorista, las mismas que agudizan la baja rentabilidad registrada en la mayor parte de estos cultivos.

Para fines de los 1990 existe un escenario signado por una débil presencia del Estado, el posconflicto armado y el narcotráfico; factores que influyen en los cocaleros del VRAE, afirmando su tendencia a antagonizar y relativizar la legalidad existente. Si bien superada la etapa de violencia la organización se reconstruye, la identidad del actor es débil y varía sin problemas de un componente a otro (de autodefensa a cocalero), volviéndose difusa y 
poco consistente. El cambio en el nombre de la organización de FEPOHCRA (productores de hoja de coca) a FEPAVRAE (productores agrarios) revela estas variaciones según la coyuntura. Ante las amenazas de erradicación, por ejemplo, no se defiende la producción desde la revalorización y el autorreconocimiento, optándose por diluir la condición de cocalero en nuevos membretes. La capacidad de organización autónoma no conlleva entonces la construcción de una identidad definida, manejándose las alianzas y los discursos de acuerdo a las necesidades del momento. Pasemos ahora a analizar cómo se define el adversario a interpelar en la movilización y qué estrategias priman en la acción colectiva.

\section{CONSTRUYENDO ADVERSARIOS; ESTRATEGIAS PRAGMÁTICAS, ENEMIGOS DIFUSOS}

En un escenario de posguerra, donde la dinámica de autodefensa pasa a un segundo plano recuperando su primacía la agricultura, los productores se organizan y vuelven a la movilización, planteándose una serie de estrategias que incluyen la definición de nuevos adversarios. Teniendo en cuenta lo afirmado por Touraine, respecto al principio de oposición que guía a los movimientos sociales, enfrentándolos por la dirección del proceso histórico de desarrollo, veamos qué sucede en el caso cocalero. No olvidemos que hablamos de un contexto donde el fujimorismo y las Fuerzas Armadas prestan especial atención a la zona proponiendo crear, sobre los distritos del VRAE la «Provincia de la Pacificación». La idea no se concreta pero, sea por cálculo político o por presión regional, el gobierno de Fujimori crea 6 de los 9 municipios distritales hoy existentes en el Valle, e instala instituciones como FONCODES o el PRONAA, puntas de lanza en el trabajo asistencial directo con la población. Funciona también el PAR para el apoyo a desplazados y se busca fortalecer la actividad municipal, promoviendo la Asociación de Municipalidades del Valle del Río Apurímac Ene (AMUVRAE), que agrupa los distritos de Pichari, Quimbiri, Sivia, San Francisco, Santa Rosa y Llochegua, y el Centro Poblado de Palma Pampa.

Se constituye así un nuevo escenario en el cual los actores sociales tienen que convivir y relacionarse. En el caso de los cocaleros agrupados en la FEPOHCRA, la situación en 1995 es crítica a raíz de la caída de los precios de la coca, que llega a costar S/. 0,41 el kg. Esta crisis, que impide que los cultivos de coca ampliados durante la guerra encuentren salida en el mercado ilegal o en ENACO, se debe sobre todo al desmantelamiento del cartel de Cali y una virtual sobre saturación del mercado mundial de cocaína. En este período además, se promulga el DS 8294-PC que otorga la más alta prioridad a la reducción de cultivo con fines ilícitos y al desarrollo alternativo. Dicho decreto se basaba en la «Doctrina Fujimori»2, que promulga el «Plan Nacional de Prevención y Control de Drogas» con cuatro componentes principales: prevención y rehabilitación del consumo, represión de tráfico ilícito, desarrollo alternativo en zonas de cultivos ilícitos y revalorización y revisión del status actual de la hoja de coca en las convenciones internacionales.

Tengamos en cuenta que el período de violencia facilitó el incremento de las hectáreas de coca, debido a las urgencias de las autodefensas y el relajamiento en la interdicción del narcotráfico. Superado el conflicto, los controles policiales se hacen más estrictos y la presencia militar ajusta la coordinación con los DECAS, perdiendo éstos parte de la

2 La denominada "Doctrina Fujimori" para combatir el narcotráfico fue elaborada con el concurso de Hernando de Soto. Según esta doctrina el problema es ante todo de carácter mercantil por lo que se destaca la necesidad de impulsar actividades económicas alternativas que permitan el desarrollo de "una real economía de mercado". Véase Cotler, 1999. 
autonomía de la que gozaron los años anteriores. Se suma a esto las constantes amenazas de fumigación que amenazaban replicar lo sucedido en el Huallaga, corriendo también rumores sobre la presencia del hongo fusarium oxysporum o de la «seca seca» esparcido por las chacras, según los agricultores, en «pastillitas blancas».

\section{Cuadro 2 - Evolución de la producción de coca el valle Río Apurímac}

\begin{tabular}{|c|c|c|}
\hline Años & $\begin{array}{c}\text { Producción } \\
\text { TM }\end{array}$ & Var \% \\
\hline 1997 & 39300 & $-10,07$ \\
\hline 1998 & 24300 & $-38,17$ \\
\hline 1999 & 21100 & $-13,17$ \\
\hline 2003 & 17400 & \\
\hline
\end{tabular}

Fuente - Narcotic Affaire Section-NAS.

Ante los bajos precios de la hoja de coca, mayor control estatal y amenazas de erradicación forzosa, los agricultores de la FEPOHCRA optan por asumir estrategias de acción que permitan sobrevivir al productor por lo menos hasta que los precios se estabilicen. Entre 1995 y 2000, se abre una estructura de oportunidades que permite a la Federación desarrollar una estrategia de coordinación y acercamiento con los entes encargados del desarrollo alternativo, tanto estatales como de la cooperación internacional. Los dirigentes de turno optan por agenciarse de los recursos de los programas de cooperación, pese al cuestionamiento de sectores al interior de la organización, que consideran esta decisión como una claudicación ante un Estado que jamás los apoyó en sus principales problemas. Al respecto el señor Francisco Barrantes, ex secretario peral FEPOHCRA menciona:

«Hubieron muchas amenazas de erradicación pero no se concretaron, nosotros, estratégicamente para que no desaparezca la coca hemos traído a la cooperación internacional. Cuando en 93, 94 después de fumigar Alto Huallaga le tocaba al VRAE, la única alternativa era traer a la cooperación y aceptar abiertamente el desarrollo alternativo y eso fue lo que hicimos, pese a cierta oposición».

Se ejecutan en el Valle del río Apurímac proyectos de desarrollo alternativo financiados por el Fondo de Naciones Unidas, el Fondo Perú Canadá, AID, la cooperación alemana (GTZ), entre otros. Por lo general, estos proyectos ensayan mejoras para los cultivos de café, aunque a decir de los agricultores, introducen variedades que no consiguen adaptarse. Se intentó también alentar el cultivo de arroz, sin tomar en cuenta que la zona, a diferencia del Huallaga, no es apta para el riego intensivo y la experiencia fracasó. La promoción del cacao dio mejores resultados, por lo que desde 1995, cuando Naciones Unidas alentó su difusión, la mayoría de cooperativas continúa el cultivo y comercialización de este producto (Cabieses, 1996).

Los proyectos de desarrollo alternativo ensayan, de este modo, la promoción de una serie de cultivos bajo el esquema de «producto motor», que había fracasado los años previos al estallido de violencia, con el boom del café primero y del cube después. Antes que plantear cambios más profundos enfocados a cambiar la economía de la coca — con sus diversas redes de comercialización y generación de empleos directos y conexos- se privilegia la sustitución del cultivo en una visión reduccionista del problema. No obstante, se vivía una aparente calma social, por los bajos precios de la hoja y la reducción de las áreas cultivadas, influyendo en esto la imposición de cuotas de compra por parte de los narcotraficantes; el productor ya no puede incrementar su producción, pues no es seguro que toda su cosecha sea comprada. 
La coordinación entre la FEPOHCRA y las instituciones promotoras del desarrollo alternativo lleva a pensar que en el VRAE la tendencia a sustituir cultivos de coca era irreversible y contaba con el apoyo de los campesinos, que, antes que adversarios, habían encontrado aliados. A decir de algunos profesionales de la zona ${ }^{3}$, las buenas relaciones entre la cooperación internacional y la Federación de Productores se reflejarían en los cuantiosos fondos que recibe y con los cuales compran vehículos, una estación de radio y construyen el local central en Pichari. La relación con el Estado es también fluida y de cercanía, coordinándose vía CONTRADROGAS una serie de acciones conjuntas. No olvidemos que entre 1995 y 2000 el gobierno de Fujimori se caracteriza por sus esfuerzos de ampliar su base social implementando para ello políticas asistenciales. El apoyo a los DECAS o la FECMAVRAE (Federación de Clubs de Madres del VRAE), vía el PRONAA o FONCODES, es por ello un eje prioritario. Se promociona además la «participación directa» en contra de cualquier intermediación política; los problemas entre cocaleros y el Estado se resuelven directamente con el jefe de CONTRADROGAS.

El panorama de coordinaciones y alianzas varía radicalmente desde mediados del 2000 , en que gana terreno la corriente opositora a la gestión de la FEPOHCRA y su apoyo abierto a los programas del desarrollo alternativo. Los ánimos opositores se exacerban al punto que, luego de diversas protestas, los agricultores contrarios a Barrantes — que cursaba su tercer periodo consecutivo como dirigente - toman por asalto el local de la Federación. En dichas acciones se evidencia también un cambio sustancial en la participación, pues hasta antes de estos sucesos, la presencia de los socios de la FEPOHCRA era más bien tangencial, privilegiándose las Autodefensas como espacio de deliberación o identificación pública. Para inicios del 2001, la oposición liderada por Fermín Hilario destituye a Barrantes bajo acusaciones de robos y malversación de los fondos de la cooperación internacional, nombrando una Junta Transitoria que cambia el nombre a FEPAVRAE. Solo ocho meses después, Hilario es destituido, acusado de «venderse» a la cooperación, nombrándose una nueva junta con Antonio Laynes, como secretario general y Nelson Palomino como subsecretario. En ambas ocasiones las acusaciones de cercanía a las agencias cooperantes operan como síntomas de traición a los intereses campesinos.

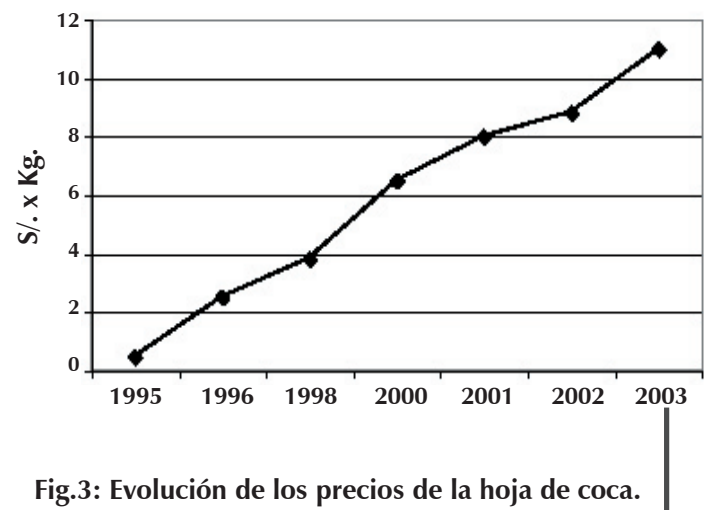

Elaboración: Anahí Durand

Fuente: Oficina monitoreo y evaluación CONTRADROGAS
Son varios los factores que confluyen en este viraje que acaba por definir a los Programas de Desarrollo Alternativo (PDA) y los organismos encargados de financiarlos o ejecutarlos, así como los adversarios que enfrentan en la acción colectiva. En primer lugar se halla la recuperación del precio de la hoja de coca en el mercado internacional a partir de 1999, ante una recomposición de las redes del narcotráfico, luego del fin de los carteles colombianos y una leve alza de la demanda. Las redes de narcotráfico se recomponen con mayor presencia de firmas mexicanas, que tienen formas más sutiles y compartimentadas de operar. De otro lado, se amplía el mercado de cocaína, enfocándose a Asia y Europa oriental como los nuevos centros de compra. Todo esto coincide con la caída

3 Entrevista al ingeniero Ciro Moreira; Huamanga, agosto del 2004. 
de los precios del café y el cacao, principales productos introducidos en la zona por el desarrollo alternativo que, pese a los años y el esfuerzo invertido, no superan la rentabilidad de la coca.

En segundo lugar, destacan los cambios en la política antidrogas; se crea DEVIDA en reemplazo de CONTRADROGAS con una estrategia que privilegia la intermediación vía ONG operadoras. Las ONG optan por coordinar con municipios y pobladores, a quienes, a cambio de suscribir compromisos para la autoerradicación de cocales, ofrecen un paquete de obras y servicios. Esto genera enfrentamientos al interior de las comunidades, donde quienes no cultivan coca aceptan el ofrecimiento en perjuicio de quienes sí lo hacen. Se contraponen dos concepciones distintas del desarrollo: una como obras de infraestructura y otra como posibilidades de sobrevivencia. Dos posiciones que enfrentan, de un lado, a la cooperación internacional y al Estado y de otro a los agricultores cocaleros. Al respecto, Alejandro Gutiérrez actual secretario general de la FEPAVRAE señala:

«Lo que ha hecho Chemonix es entrar a comunidades que no tienen coca, hacer que la comunidad apruebe y obligar a erradicar, eso es lo que está pasando y a cambio se hacen carreteras, una serie de beneficios para los no cocaleros, y así se benefician más los que no siembran. Desde el inicio que se ha dado el desarrollo alternativo en el Valle, el que se ha beneficiado es el que no tiene coca, y el cocalero la pasa peor, eso ha polarizado mucho».

En tercer lugar, se cuenta la transición democrática, que abre una nueva estructura de oportunidad, permitiendo a los campesinos mayores márgenes de expresión y movilización. No olvidemos que, como parte del estado de emergencia en el VRAE, hasta fines del 2000 estuvo prohibido organizarse sin el consentimiento del Comando Político Militar. Por tal razón, prácticamente las únicas organizaciones con posibilidades reales de acción eran los DECAS y, posteriormente, alentados por el gobierno, los Clubes de madres. Finalmente, un cuarto elemento es la influencia en algunos dirigentes del discurso pro cocalero basado en la experiencia boliviana. Si bien en su mayoría las bases están al tanto de esta experiencia, líderes como Nelson Palomino, ven en la reivindicación y defensa del cultivo ancestral de la coca una veta por explotar, enfilando hacia ello los esfuerzos durante su gestión.

A partir del 2001, durante la gestión de Laynes y Palomino, es la lógica confrontacional y polarizadora la que prima en el accionar de la FEPAVRAE. Hábilmente y haciendo uso de una radio local, el medio de comunicación más utilizado en los espacios rurales, Nelson Palomino inicia una labor de concientización, propaganda y agitación. Las baterías apuntan contra la gestión de CARE como ONG operadora del PDA en el VRAE, con fondos sobre todo de USAID. Vale mencionar que CARE se había venido manejando con poca prudencia, dando lugar a acusaciones de displicencia, ostentosidad y derroche de recursos que no beneficiaban directamente a los agricultores. La contratación de ingenieros y otros empleados con sueldos en dólares, para la gente del valle resultaba excesiva, así como los beneficios de vacaciones y descansos adicionales que gozaban. Esto, presentado por la radio en quechua y con particular elocuencia radical, genera la adhesión de los pobladores que asocian a las ONG y su personal como los únicos beneficiarios del PDA y la cooperación; profesionales que viven bien a costa de la erradicación de sus cocales.

Antes que la injerencia norteamericana en política antidroga, decisiones estatales erradas del gobierno peruano, o la intromisión de la cooperación extranjera, el enemigo son las ONG en general y CARE Perú en particular. El discurso que diferencia cocalero de narcotraficante y revalora la hoja de coca por su carácter milenario haya eco en campesinos temerosos de la erradicación, con ansias de revalorar su labor agraria y hallar explicaciones a los escasos resultados obtenidos con el desarrollo alternativo. Se suceden una serie de 
manifestaciones y protestas cuyo punto de llegada es el local de CARE, el mismo que finalmente es quemado, debiendo retirarse esta institución de la zona. Meses después, en una de estas movilizaciones, los cocaleros, con Palomino a la cabeza, van a la radio opositora (que difundía avisos de CARE), atentando contra la integridad de uno de sus periodistas. Esta es la razón por la que Palomino es detenido en febrero del 2003 y condenado a 14 años de prisión, recluido en el penal de Yanamilla (Ayacucho).

La detención de Nelson Palomino detiene un ciclo de politización acelerada y creciente confrontación. El vacío de dirección producido se evidencia en las pugnas internas que acompañan la gestión de Maricela Guillen, quien asume como secretaria general de la FEPAVRAE hasta agosto del 2004. Sin embargo, pese a las disputas por la dirección, hay consenso en continuar señalando a las ONG operadoras como el principal adversario a enfrentar. Las críticas al gobierno son más bien tangenciales, no teniéndose claro qué roles le competen al Estado y cuáles a las ONG, dirigiéndose a estas prácticamente la totalidad de las demandas. Este desconocimiento demuestra, además, una precaria formación política, incapaz de reconocer lo básico del funcionamiento estatal o las instancias administrativas, y una profunda desconfianza de los entes de intermediación (partidos políticos), completamente al margen durante las movilizaciones.

Vemos que la organización y sus dirigentes aprovechan las diferentes estructuras de oportunidad para posicionar determinada tendencia y definir los adversarios. Sin embargo, antes que por la dirección del proceso histórico de desarrollo, los cocaleros parecieran enfrentarse más bien por conseguir beneficios inmediatos. Altas dosis de pragmatismo se imponen en el accionar cocalero, pues mientras el precio de la hoja de coca es bajo, no se rechaza el desarrollo alternativo. Es cuando los precios suben que se inician los conflictos, coincidiendo además con determinadas aperturas del sistema político. Sin duda, la precariedad económica y una politización influenciada, primero, por el autoritarismo de la guerra y, luego, por el asistencialismo fujimorista influyen en las estrategias de acción, llevando a identificar a adversarios inmediatos y dificultando ver el trasfondo histórico y geopolítico de la problemática. Pese a que algunos líderes pretenden incorporar elementos de carácter étnico o cultural, sus esfuerzos se truncan tan pronto se alejan de la organización — voluntaria o involuntariamente-. Detengámonos ahora en cómo se socializan las reivindicaciones a la sociedad y qué caracteriza la interacción con el Estado.

\section{SOCIALIZANDO EL CONFLICTO: INTERACCIÓN ESTADO - SOCIEDAD CIVIL}

En este escenario de politización pragmática, adversarios difusos e identidades tenues, los esfuerzos de los cocaleros por lograr que sus demandas transciendan al resto de la sociedad regional y/o nacional han estado signados por la fragmentación y el aislamiento. Se han hecho evidentes así serias dificultades para hacer parte de su problemática a otros sectores, a diferencia de lo que sucede en el caso boliviano, donde muchas de las reivindicaciones cocaleras tienen que ver con demandas nacionales de identidad cultural o soberanía (Arrueta, 1994). Más que una estrategia para generar involucramientos de otros sectores, capaces de enriquecer la acción, la FEPAVRAE opta por relacionarse con quienes puedan cubrir determinadas necesidades de corto plazo, sin una agenda política clara que oriente la interacción con dichos aliados y, menos todavía, con el Estado.

Para entender mejor las dificultades de los cocaleros del VRAE para superar lo sectorial, y trascender a la colectividad bajo el principio de totalidad que sugiere el enfoque de los nuevos movimientos sociales, veremos lo actuado en dos niveles. El primero se refiere a las 
coordinaciones emprendidas con cocaleros de otras cuencas, a fin de constituir un gremio nacional que eleve sus posibilidades de incidencia. El segundo nivel tiene que ver con las relaciones entabladas con otros gremios campesinos o de trabajadores, de alcance nacional y/o regional, en la perspectiva de consolidar alianzas estratégicas. A partir del análisis de estos dos procesos, nos detendremos finalmente en las características de la interacción con el Estado y sus instituciones.

La unificación de los cocaleros en una organización nacional no ha podido concretarse hasta hoy, primando las organizaciones de carácter local, no siempre dispuestas a tejer articulaciones mayores. Históricamente, son los campesinos cocaleros de la zona oriental del Cusco los primeros en organizarse, creando la Federación Provincial de Campesinos de la Convención, Yanatile y Lares (FEPCACYL) en 1958. Su fundación se realiza al calor de las protestas contra el dictamen de la Organización Mundial de la Salud, que incluía a la hoja de coca entre las plantas nocivas recomendando su prohibición (CONPACCP, 2004). La FEPCACYL recibe también influencia de las luchas campesinas alentadas en la zona por Hugo Blanco durante los años 1960, por lo que hasta ahora mantiene un discurso clasista. Estos valles tienen además la particularidad de vender prácticamente la totalidad de su producción a ENACO, con fines de consumo tradicional.

Este status de «Cocaleros legales», hace que la FEPCACYL sea reacia a coordinar con otros cocaleros, a quienes considera cercanos al narcotráfico. Los cocaleros del Huallaga siguen así otro derrotero organizativo, presionados además por las posturas antinarcóticos del gobierno norteamericano. En función de la «guerra contra las drogas» enunciada por EEUU, en 1964 el gobierno peruano promulga el DS 254 que limita las zonas autorizadas de producción de coca a algunos distritos de los departamentos de Cusco, Ayacucho y Huánuco. Posteriormente, en 1978, se promulga el DL 22095, que avala los operativos antinarcóticos Verde Mar I y II, con altos saldos en violaciones a los derechos humanos. La Asociación de Productores Agrarios de Leoncio Prado y Anexos (APALP-A) intenta enfrentar la situación, pero el asesinato de dos de sus principales líderes - Tito Jaimes y David Ramírez-y el débil apoyo de otras organizaciones nacionales frenan su intención.

El conflicto armado interno refuerza esta desconexión entre los principales gremios cocaleros del país, en tanto los intereses del Partido (Sendero Luminoso) se sobreponen a los sectoriales, creándose desde una visión sobreideologizada Frentes de Defensa (FEDIPS) y/o Comités Populares, que ordenan la vida pública y privada. Las cuencas cocaleras del VRAE y el Huallaga se convierten en los escenarios más cruentos de la guerra por los ataques senderistas, la represión estatal y la presencia de sicarios del narcotráfico. Los dirigentes asesinados, campesinos torturados, asesinatos, violaciones y desapariciones se cuentan por miles, así como los daños en infraestructura (CVR, 2003: tomo 5). El periodo de guerra no favorece la coordinación entre gremios cocaleros, por el contrario, lleva a estrategias distintas de sobrevivencia donde unos optan por la autodefensa y otros por la convivencia, hasta que finalmente la subversión es derrotada.

A inicios de los años 1990, los bajos precios de la hoja y el estado de emergencia en las zonas cocaleras más importantes debilitan a los gremios locales y limitan las posibilidades de conformar una organización nacional. Esto permite el trabajo con la cooperación internacional en proyectos de desarrollo alternativo, con énfasis distintos según los valles. Asimismo, la crisis de los partidos políticos y el ajuste económico mellan la capacidad de respuesta, incrementando la dependencia de los programas asistenciales, a la vez que la «participación directa», promovida por el gobierno, perjudica a las organizaciones autónomas.

Priman, entonces, gremios o asociaciones de productores de carácter regional o local con posiciones distintas e incluso encontradas, no siempre dispuestos a entablar el diálogo 
entre sí. La dispersión y la falta de coincidencias en las agendas, así como las dificultades para identificar demandas e interlocutores comunes, destacan entre sus características, con efectos muchas veces contraproducentes para sus objetivos.

\section{Cuadro 3 - Organizaciones nacionales, posiciones y demandas}

\begin{tabular}{|c|c|c|}
\hline Organización & Posición & Principales Demandas \\
\hline $\begin{array}{l}\text { FEPCACYL / } \\
\text { APOCAS } \\
\text { (Cusco y Puno) }\end{array}$ & $\begin{array}{l}\text {. Posición clasista } \\
\text {. Influencia de los partidos de } \\
\text { izquierda (PUM y Patria Roja) } \\
\text {. Vinculada a las centrales } \\
\text { campesinas de sus regiones y, } \\
\text { a nivel nacional, a la CCP }\end{array}$ & $\begin{array}{l}\text {. Demandas dirigidas a ENACO } \\
\text {. Se exige sobre todo ampliación de } \\
\text { las compras o apoyo al agricultor } \\
\text { (créditos, incentivos, etc.) } \\
\text {. Poco dispuesta a vincularse con } \\
\text { otras organizaciones cocaleras }\end{array}$ \\
\hline $\begin{array}{l}\text { FEPAVRAE } \\
\text { (Ayacucho) }\end{array}$ & $\begin{array}{l}\text {. Posiciones variantes y apolíticas } \\
\text {. Existe en algunas bases } \\
\text { simpatía por el fujimorismo, } \\
\text { no siempre coincidentes con } \\
\text { las posturas de los líderes }\end{array}$ & $\begin{array}{l}\text {. Demandas dirigidas principalmente } \\
\text { contra DEVIDA, las ONG operadoras } \\
\text { y la cooperación internacional } \\
\text {. En las exigencias se pide el fin } \\
\text { de los Programas de Desarrollo } \\
\text { Alternativo y cierre de DEVIDA }\end{array}$ \\
\hline $\begin{array}{l}\text { APHOC-Tocache / } \\
\text { APALP-A } \\
\text { (Alto Huallaga) }\end{array}$ & $\begin{array}{l}\text {. Posiciones radicales y anti } \\
\text { norteamericanas, no llegan a ser } \\
\text { clasistas, polarizan fácilmente } \\
\text { entre los intereses extranjeros y } \\
\text { los propios en el tema de la coca. }\end{array}$ & $\begin{array}{l}\text {. Las demandas se dirigen } \\
\text { principalmente al Ministerio del } \\
\text { Interior y a DEVIDA. Exigen el } \\
\text { cese de la erradicación forzosa y el } \\
\text { replanteamiento de los Programas } \\
\text { de Desarrollo Alternativo. }\end{array}$ \\
\hline APAVM (Monzón) & $\begin{array}{l}\text {. Posición de radical rechazo } \\
\text { frente al Estado, lindando con una } \\
\text { defensa tácita del narcotráfico }\end{array}$ & $\begin{array}{l}\text {. Las demandas son dirigidas al Estado } \\
\text { y sus instituciones. Tienen que ver con } \\
\text { el cese a la erradicación forzosa y los } \\
\text { operativos de interdicción en la zona }\end{array}$ \\
\hline
\end{tabular}

Elaboración - Anahí Durand / Fuente - Entrevistas realizadas

No obstante, con la reanudación de los operativos de erradicación forzosa en Aguaytía y el Alto Huallaga (Tocache) en 1998 (Ministerio del Interior), se retoman con mayor decisión las coordinaciónes entre los distintos valles. En febrero de 1998 se funda en Lima la Coordinadora Nacional de Productores Agropecuarios de las Cuencas Cocaleras del Perú (CONAPA-Perú), agrupando a ocho Federaciones y Asociaciones incluida la FEPOHCRA y la APALP-A. También se afilian la OARA (Asháninkas del río Apurímac) y cuatro asociaciones de mujeres campesinas del VRAE, Tingo María, Uchiza y Monzón respectivamente (Cabieses, 2003). En este evento, los delegados eligen como presidente de la CONAPA a Francisco Barrantes (Pachín) del Valle del Apurímac.

Los problemas en la FEPAVRAE, que terminan con la salida de Barrantes y el ascenso de Palomino, influyen en la desactivación de la CONAPA, lo mismo que la decisión del gobierno de negociar por separado con cada cuenca a través de Mesas de Diálogo regionales. En el mismo sentido, las aperturas de la transición democrática facilitan el posicionamiento de una generación de líderes con posturas muy críticas y radicalizadas, tales como Nelson Palomino en el VRAE, Nancy Obregón o Elsa Malpartida en el Huallaga. Coincide además con una gestión de DEVIDA abierta al diálogo con los productores, presidida por Ricardo Vega Llona. Es en una de estas reuniones de coordinación convocada por DEVIDA, a la que asisten muchos dirigentes cocaleros de las distintas cuencas del país, que se funda 
la Confederación Nacional de Productores Agropecuarios de las Cuencas Cocaleras del Perú (CONPACCP). Posteriormente, en enero del 2003, se realiza el I Encuentro Cocalero Nacional en Lima, donde las cuencas cocaleras más representativas 4 ratifican la creación de la CONPACCP, nombrando a Nelson Palomino como su secretario general.

Si bien la CONPACCP fue el esfuerzo más conocido de unificación, debido a acciones como la marcha de sacrifico a Lima en marzo del 2003 —en la que se movilizaron más de 6000 campesinos forzando a Toledo a recibirlos en Palacio de Gobierno-, la unidad conseguida fue bastante efímera. Una serie de desavenencias y conflictos por mantener cuotas de poder local impiden reconocer y legitimar dirigencias nacionales. Tampoco se consigue construir una agenda única pues, de un lado, Monzón rechaza la interdicción, el VRAE insiste en la salida de las ONG operadoras y el Huallaga reclama el empadronamiento a ENACO, sin lograr concertar prioridades comunes. Esto, sumado a discusiones sobre el destino de fondos obtenidos para la marcha de sacrificio, produce la primera fractura de la CONPACCP durante su II Congreso Nacional realizado en febrero del 2004 en Lima. Los cocaleros del VRAE dirigidos por Marisela Guillen no asisten al evento, desconociendo a la directiva, mientras los cocaleros de Monzón se retiran violentamente.

Más aún, la detención de Nelson Palomino en febrero del 2003, líder que actúa como factor de unidad, deja enfrentadas a las cuencas más importantes, enfrascadas en discusiones por el respaldo del dirigente encarcelado. La intervención de actores políticos externos aporta también a los desencuentros, influyendo en uno y otro sector con el fin de incrementar sus bases políticas. Es el caso del congresista apurimeño Michel Martínez con el grupo Yapansuyo o Ricardo Noriega, que se ofrece como abogado de Palomino a cambio de su adhesión política5. En suma, las precarias identidades, la imposibilidad de visualizar problemáticas y adversarios comunes, así como la ausencia de una agenda que los unifique más allá del simple pliego reivindicativo, dificulta activar y organizarse a nivel nacional. Consuman la ruptura las frecuentes acusaciones, no probadas, de recibir dinero de la cooperación internacional y la intromisión interesada de asesores y políticos. Al respecto, son ilustrativas las declaraciones de Maricela Guillen:

«No se ha constituido el gremio nacional, la CONPACC, no tiene registro público y otros valles como Quillabamba o Monzón no quieren saber nada con ellos porque ha sido constituido por pocas personas, y su directiva se ha elegido por unos cuantos. Además las dirigentas viven con los fondos de DEVIDA y no se puede apoyar eso, en Ayacucho las hemos cuestionado. A Huamanga llegaron ellas y no hubo entendimiento, yo lo he visto en la marcha a Lima; paraban pidiendo dinero y eso a mí me ha hecho entender que vivían con dinero de DEVIDA».

De otro lado, las relaciones con otros gremios campesinos y de trabajadores como la Confederación Campesina del Perú (CCP) o la Confederación General de Trabajadores

4 Entre los principales valles que agrupó la CONPACC en sus inicios se cuentan el valle del Apurimac Ene (12 000 afiliados) Alto Huallaga Uchiza (2 000), Alto Huallaga Puerto Pizana (1 500), Alto Huallaga - Aucayacu (3 000), Alto Huallaga-Tingo María (3 000), Aguaytia (1 200), Pichis Palcazú (1 000), Monzón (2 500) y Jaén San Ignacio (300). Quedaron fuera de la CONPACCP por decisión propia los agricultores cocaleros nativos o colonos de la FEPCACYL (10 000), Bajo Urubamba (1 000), Sandia (2 000), Huallaga Central (500), Bajo Huallaga (300) y Alto Marañón (2 000). (CONAPACC, 2004).

5 Comentario personal de Hugo Cabieses, actual asesor de la CONPACCP; Lima, julio 2004.

Michel Martínez, congresista por el departamento de Apurímac, ha creado el partido Yapansuyo, de corte indigenista, incorpora la revaloración de la hoja sagrada como una de sus principales reivindicaciones. Ricardo Noriega, ex candidato presidencial en 2000 por una agrupación vinculada al fujimorismo, se ofreció como defensor de Nelson Palomino a cambio de que la FEPAVRAE lo apoye con la recolección de firmas necesarias para la inscripción legal correspondiente. 
del Perú (CGTP) han sido escasas y básicamente declarativas. En el Perú (y esta es otra diferencia con el caso boliviano) los gremios, sindicatos y dirigentes ligados a la izquierda clasista, no han mostrado mayor interés en incorporar a los cocaleros en sus luchas, teniendo una posición poco clara sobre el tema. De parte de los cocaleros tampoco han existido esfuerzos decididos por vincularse a estas organizaciones ni por exigir apoyos más efectivos y concretos en las diferentes acciones emprendidas. A lo mucho, las alianzas o coordinaciones son a nivel local, como en el caso del VRAE, donde la mayoría de acciones cuentan con la participación de la FECMAVRAE, organización en la que participan las familias del valle. A nivel regional, no se han consolidado alianzas con organizaciones sociales de Ayacucho, algo que podría dotar de dimensión regional al problema cocalero.

A nivel nacional la situación es similar, pues la CONPACCP, en las dos marchas de sacrifico realizadas a Lima, contó más con el apoyo de universitarios y pequeñas agrupaciones nacionalistas6, que de organizaciones gremiales institucionalizadas (sindicatos o gremios campesinos). Si bien algunas de estas organizaciones manifestaron su respaldo, este fue sobre todo declarativo, y tampoco los dirigentes cocaleros insistieron en una acción conjunta real. Dichos desencuentros alimentan la fragmentación persistente en la sociedad peruana y se nutren de factores como la crisis de los partidos políticos y las organizaciones sociales, llevando a los cocaleros a evaluar con desconfianza el acercamiento de estos gremios. En tal sentido Elsa Malpartida, secretaria de organización de la CONPACC, afirma:

«Otros gremios tampoco han apoyado, todos son partidarizados, con intereses políticos, cada quien lleva agua a su molino, ven que podemos estar alcanzando cierto nivel y podemos ensombrecer su liderazgo. Cuando estuvimos en Lima la CGTP y otros gremios ofrecieron apoyo, pero todo muy declarativo nunca un apoyo real de que vamos a luchar hombro a hombro a pesar de que vienen y discursean, no hay un apoyo real, hasta el financiamiento es propio».

A escala internacional, se formó en marzo de 1991 el Consejo Andino de Productores de Coca (CAPHC) que agrupa a cocaleros de Bolivia, Perú y Colombia con sede en La Paz. Desde su fundación, la directiva se halla integrada por su presidente Evo Morales (Bolivia), Francisco Barrantes (Perú) y Omaira Morales (Colombia). El CAPH ha actuado más como un foro de discusión y, desde 1998, no ha vuelto a reunirse ni cambiado de dirigencia. En Perú, existe interés de un sector de cocaleros (el Huallaga) por darle un nuevo impulso, aunque tal intención no sea compartida por la dirigencia del VRAE. En todo caso, no es que se privilegien alianzas a nivel internacional en desmedro de articulaciones nacionales, la relación con la organización boliviana por ejemplo ha sido más bien distante, negando Evo Morales en sucesivas oportunidades cualquier vinculación con sus pares peruanos.

La actual división de las organizaciones cocaleras y la imposibilidad de ampliar la acción a la sociedad hace que la interacción con el Estado sea por lo general conflictiva y desventajosa para los productores. Teniendo en cuenta que la política estatal frente al tema coca es más bien coercitiva — le compete al Ministerio del Interior-, las posibilidades de lograr atención a las demandas exacerbando el conflicto son escasas, pues los actos de enfrentamiento, si bien pueden ser efectistas, al mediano plazo evidencian las debilidades organizativas. Esto se vio en la marcha de sacrificio (mayo 2004), donde los cocaleros de la CONPACC, luego de cinco semanas en Lima, se retiraron sin siquiera haber sido atendidos por el ejecutivo.

6 Durante la segunda marcha de sacrificio (abril-mayo de 2004), se forma la "Coordinadora de Solidaridad cocalera", integrada por grupos universitarios (Otro mundo es posible, Raíz, FER, etc.) y grupos nacionalistas como Panaca o el Movimiento Etnocacerista. Sin embargo, luego de que los agricultores regresaron a sus cuencas, este espacio no ha tenido mayor vida orgánica. 
Las limitaciones de los gremios cocaleros, además, son aprovechadas por entes estatales como DEVIDA, que crean sus propias asociaciones de productores. A nivel de gobiernos locales, la fragilidad institucional imperante lleva a que los intereses de los alcaldes definan la coordinación o no con los gremios cocaleros. En el caso del VRAE, mientras primó la lógica confrontacional, hubo un apoyo coincidente con las amenazas de revocatorias levantadas por algunos dirigentes. Posteriormente, luego de la detención de Palomino, los municipios de la AMUVRAE toman distancia de los cocaleros, a sugerencia de USAID que también financia muchos de los proyectos que se ejecutan en su jurisdicción.

No debemos olvidar tampoco que en materia de política antidroga, el estado Peruano se mueve en los estrechos márgenes que le permite el gobierno de los Estados Unidos. En el área andina, las políticas nacionales contra las drogas han estado enmarcadas por la doctrina de «guerra a la cocaína» norteamericana, sustentada en una visión conservadora e intervensionista por la cual EEUU se ocupa de la región. Esta concepción, que enfatizaba la acción policial, no dio los frutos esperados por lo que veinte años después, a inicios de los 90, empezó a hablarse de desarrollo alternativo y «responsabilidad compartida» (Boville Luca de Tena, 2000). En adelante para los Estados Unidos, los gobiernos de la región andina deben combinar acciones de erradicación de cultivos, operativos de interdicción y programas de desarrollo que ofrezcan incentivos a las comunidades cocaleras para que opten por dejar el sembrío de coca. El peso de la influencia norteamericana en cuestión de coca, no es un secreto, aunque los cocaleros del VRAE no perciban la dimensión de los intereses en juego.

Concluyendo, las organizaciones cocaleras presentan serias dificultades para actuar bajo el principio de totalidad mencionado por Touraine, y entendido como la capacidad de los movimientos para socializar sentidos alternativos, susceptibles de trascender a la sociedad. Los cocaleros del VRAE parecieran configurar ante todo protestas sectoriales, marginales del resto de la sociedad civil y con posiciones ambiguas en la interacción con el Estado. Así, a la vez que se exige mayor atención estatal en materia de servicios y política agraria, se rechaza el componente coercitivo, oponiéndose a cualquier presencia estatal que signifique un riesgo para sus cultivos, frecuentemente utilizados con fines ilícitos. Lo que encontramos son organizaciones capaces de identificar estructuras de oportunidad, movilizar recursos y estrategias, pero sin una clara identificación de expectativas comunes, adversarios e interlocutores, lo cual, sumado al caudillismo local, el pragmatismo y la urgencia coyuntural complica el hablar de la existencia de un «movimiento cocalero» en el VRAE.

\section{REFLEXIONES FINALES, LA INSISTENCIA DE LA VOLUNTAD}

$\mathrm{Al}$ abordar el tema de la organización cocalera y su constitución como movimiento social, antes que pretender simplemente encuadrar la acción de estos campesinos en lo anotado por la teoría sociológica, nos interesa acercarnos a la complejidad de los conflictos sociales en el Perú pos fujimorista. Tratamos de evaluar a la vez qué tanto aportan estas luchas a la democratización de la sociedad peruana y cómo Estado y sociedad trabajan por incluir a ciudadanos generalmente tratados como de segunda categoría. Los campesinos de las cuencas cocaleras han visto constantemente relativizados sus derechos, como sucede hoy con el PDA que, a cambio de la construcción de colegios o carreteras, exige suscribir acuerdos de erradicación, soslayando el deber del Estado de impartir estos servicios. Se busca, entonces, problematizar en el tema cocalero desde su dimensión social y política, aportando pistas para la comprensión de un actor que convive con la violencia y que ha recibido por parte del Estado sobre todo represión y condicionamientos. 
A lo largo del artículo, desde la experiencia del valle del Apurímac, hemos estudiado la dinámica de las organizaciones cocaleras peruanas, caracterizadas por su habilidad para movilizar recursos e identificar aperturas de oportunidad, pero a la vez por su precaria identidad, dificultades para definir adversarios y la fragmentación y aislamiento frente a la sociedad. Comparativamente, tal situación nos aleja de lo sucedido en países vecinos que, en el terreno de los movimientos sociales, han experimentado fenómenos de politización social, como es el caso del movimiento indígena ecuatoriano o el cocalero en Bolivia. Profundizar en las causas de esta particularidad peruana podría ser materia de otro ensayo. Queda pendiente afinar miradas comparativas, teniendo en cuenta la repercusión regional de las experiencias y sus posibles conexiones, cosa que, en el caso de la supuesta relación entre cocaleros andinos, pareciera no haber pasado del interés de algunos dirigentes peruanos por sacar ventaja discursiva de los logros bolivianos.

Resaltamos así la dificultad para hablar de la existencia —o afirmar la inexistenciadel movimiento cocalero en el Perú. Lo cierto es que contamos con organizaciones de productores de hoja de coca, capaces de desplegar en la movilización una serie de recursos, aunque no logren producir un sentido alternativo de la acción sobre la base de los principios de identidad, oposición y socialización mencionados. Así, por ejemplo, se movilizan aportes de los afiliados para las marchas de sacrificio a Lima y se reconocen las oportunidades más apropiadas para hacerlo. No obstante, respecto al principio de identidad como factor de reconocimiento, en los cocaleros del VRAE, fruto de conflictos y situaciones ya mencionadas, prima el pragmatismo al momento de la identificación, sin que se disputen sentidos alternativos de la acción o cuestionen marcos culturales imperantes. Tal situación, extensible a otras cuencas, genera dinámicas polarizantes, apremiadas por las urgencias del contexto. Sin embargo, ipuede revertirse esta tendencia en escenarios donde las políticas estatales son sumamente variables, la economía depende de factores externos (narcotráfico, cooperación) y no hay actores que impriman orientaciones de sentido a una política caracterizada por ceder a la corrupción y el coyunturalismo?

De otro lado, las dificultades de los cocaleros para definir adversarios conlleva la imposibilidad de configurar miradas estratégicas y establecer alianzas que potencien la acción. La lucha, antes que por la dirección del proceso de desarrollo, es más bien por lograr beneficios inmediatos, relacionados con problemas locales como el mal uso de los recursos de la cooperación; no es la crítica a un modelo excluyente, sino a quienes lo administran. Basado en estas limitaciones, el Estado minimiza la organización cocalera, decidiendo, sin mayor consulta y pese a los escasos resultados, seguir las mismas estrategias. ¿Por qué desconocer a las organizaciones cocaleras si la dispersión entorpece una negociación efectiva y de mayor alcance contra soluciones parciales muy focalizadas? Si los cocaleros manifiestan públicamente su rechazo al narcotráfico, ipor qué no arribar a estrategias concertadas que permiten enfrentarlo? La injerencia norteamericana, la escasa disposición al diálogo de ambas partes y la falta de una visión política nacional sobre el tema, son puntos de debate en las respuestas.

Tampoco al momento de socializar el conflicto los cocaleros han podido sumar logros significativos. A los esfuerzos fallidos por constituir un gremio nacional se agrega la poca integración con gremios campesinos y de trabajadores, lo cual favorece el aislamiento y disminuye la capacidad de incidencia. Estos desencuentros, hacen que la problemática cocalera sea vista como un conflicto en zonas distantes, sin mayor repercusión para el resto del país, salvo por los desmanes o problemas que originan en la protesta, ignorándose la dimensión geopolítica o de soberanía nacional. De otro lado, lleva a los cocaleros a incrementar su recelo hacia la sociedad y sus instituciones, sin buscar acercamientos que les permitan dar a conocer sus problemas, concretando alianzas e involucramientos. No obstante, ¿cómo actuar bajo un principio de totalidad en un país hoy signado por la 
fragmentación social? ¿Por qué exigir a las ONG y los gremios clasistas una coordinación real cuando los líderes cocaleros prefieren el antagonismo fácil antes que una labor de envite hacia el resto de la sociedad civil?

Restan, pues, una serie de interrogantes, cuya resolución tiene que ver con decisiones de los actores y puede tener repercusiones para el conjunto del país. No olvidemos que, pese a su escasa estructuración orgánica y claridad de orientación, organizaciones que se mueven en los márgenes de la legalidad, como las cocaleras, generan situaciones de conflicto que, bien aprovechadas por grupos políticos proclives a la violencia, podrían complicar el panorama. Sin embargo, creemos que al interior de estos gremios de productores, junto a elementos regresivos, conviven tendencias que apuestan por replantear objetivos y estrategias desde los marcos de la democracia. Si bien por ahora los elementos progresivos son muy tenues, hablamos de actores con gran capacidad de afrontar y revertir situaciones adversas. Superar el aislamiento, la primacía de lógicas que exacerban la polarización y la falta de diálogo entre la sociedad civil requiere de amplios esfuerzos de interacción que permitan recomponer los lazos sociales fracturados por la guerra y la corrupción. Si, como afirmamos, un sector de estos productores apuesta por encontrar salidas coordinadas a problemas nacionales, depende del resto de la sociedad - y del Estado- ensayar acercamientos y estrategias de democratización conjuntas. No atender a la problemática cocalera, puede llevarnos a repetir ciclos de exclusión, violencia y fragmentación social; peor aún, teniendo en cuenta que, como decía Marx muchos años atrás y muy lejos de la Amazonía peruana, la historia cuando se repite lo hace como farsa... o como tragedia.

\section{Referencias citadas}

ATLAS DEPARTAMENTAL DEL PERÚ, 2003a - Cuzco-Apurimac (Tomo 1), 200 p.; Lima: Editorial PEISA - La República.

ATLAS DEPARTAMENTAL DEL PERÚ, 2003b - Ayacucho-Ica (Tomo 8), 200 p; Lima: Editorial PEISA - La República.

ARRUETA, J., 1994 - Campesinado, Coca y Estado, Cochabamba 1987-1989, 116 p.; Cusco: Centro de Estudios regionales Bartolomé de las Casas.

BARRERA, A., 2001 - Acción colectiva y crisis política, El movimiento indígena ecuatoriano en los 90, 302 p.; Quito: Ediciones Abya Yala.

BEDOYA, E., 2003 - Las estrategias productivas y el riesgo entre los cocaleros del Valle de los ríos Apurímac y Ene. In: Procesos demográficos y ambientales: 119-153; Lima: Consorcio de Investigación Económica y Social.

BOVILLE LUCA DE TENA, B., 2000 - La guerra a la cocaína; drogas, geopolítica y medio ambiente, 285 p.; Madrid: Editorial Debate.

CABIESES, H., 1996 - Bases para una historia de la estructura productiva y social del Valle del Río Apurímac Ene, 31 p.; Documento elaborado para GTZ.

CABIESES, H., 2003 - Organización de los cocaleros: pocos pero significativos. Revista Ideele, 155: 83-86; Lima. 
COMISIÓN DE LA VERDAD Y RECONCILIACIÓN (CVR), 2003 - Informe final, 9 tomos; Lima: Comisión de la Verdad y Reconciliación.

CONFEDERACIÓN NACIONAL DE PRODUCTORES DE LAS CUENCAS COCALERAS DEL PERU (CONPACCP), 2004 - Actas del II Congreso Nacional Ordinario, Febrero del 2004; Lima. www.mamacoca.org

COTLER, J., 1999 - Drogas y Política en el Perú, la conexión norteamericana, 309 p.; Lima: Instituto de Estudios Peruanos.

DEL PINO, P., 1996 - Tiempos de guerra y de dioses: Ronderos, evangélicos y senderistas en el Valle del Río Apurímac. In: Las Rondas Campesinas y la Derrota de Sendero Luminoso (Degregori, C., ed): 117-189; Lima: Instituto de Estudios Peruanos.

MAYORGA, R., 1992 - ¿De la anomia política al orden democrático? Democracia, estado y movimiento sindical en Bolivia, 288 p.; La Paz, CEBEM.

MELUCCI, A., 1999 - Acción colectiva, vida cotidiana y democracia, 260 p; México: Colegio de México. Centro de Estudios Sociológicos.

MINISTERIO DEL INTERIOR, 2003 - Memoria de la Dirección Antidroga de la Policía Nacional del Perú 1994-2003; Lima: Oficina prensa DIRANDRO

PNUFID, 1994 - Diagnostico rural rápido del valle del Río Apurimac - Ene, 93 p.; Lima.

TILLY, C., 1993 - Movements as Historically Specific Clusters of Political Perfomances. Berkeley Journal of Sociology, 38: 1-30; California.

TOURAINE, A., 1989 - América Latina Política y sociedad, 516 p.; Madrid: Espasa Editorial.

WACHHOLTZ, R., 1996 - Economía de los sistemas agrícolas en el Valle Apurímac, Perú, Lima, 51 p.; Informe para el PNUFID.

\section{Siglas utilizadas}

CVR: $\quad$ Comisión de la Verdad y Reconciliación.

CADS - DECAS: Comités de Autodefensa- Defensa Civil Antisubversiva.

CAPH: $\quad$ Consejo Andino de Productores de la Hoja de Coca.

CONAPA: Coordinadora Nacional De Productores Agropecuarios de las Cuencas Cocaleras.

CONPACC: Confederación Nacional de Productores Agrarios de las Cuencas Cocaleras.

DEVIDA: $\quad$ Comisión Nacional para el Desarrollo y la Vida sin Drogas.

ENACO: $\quad$ Empresa Nacional de Comercialización de la Coca.

ENCl: $\quad$ Empresa Nacional Comercializadora de Insumos.

FECVRA: $\quad$ Federación de Campesinos del Valle del Río Apurímac.

EPAVRAE: $\quad$ Federación de Productores Agrarios del Valle del Río Apurímac Ene.

FEPCACYL: Federación Provincial de Campesinos de la Convención, Yanatile y Lares.

FEPOHCRA: $\quad$ Federación de Productores de Hoja de Coca del Río Apurímac.

FONCODES: Fondo Nacional de Compensación y Desarrollo Social.

PAR: $\quad$ Programa de Apoyo al Repoblamiento.

PDA: $\quad$ Programa de Desarrollo Alternativo.

PRONAA: $\quad$ Programa Nacional de Asistencia Alimentaria.

VRAE: $\quad$ Valle del Río Apurímac Ene 